Armando Donoso

\title{
Simples conversaciones con Ortega y Gasset
}

A bordo del sManuel Arniss, en el mes de Febrero de MCMXXVI ¿Era eslo la vida? ¡Bueno, venga otra vez! Nielzsche.

1901 N la vida intelectual de José Orlega y Gassel ha presidido un sino venturoso: fué el infante afortunado que encontró, desde la hora matinal. fácil para sus triunfos el camino de lerciopelo. $\mathrm{Y}$ aunque la ancianidad no ha blanqueado aún su cscasa cabellera, ya la leyenda comienza a aromar la crónica de su existencia: asi leemos en la más abultada de las enciclopedias, la historia prodigiosa de esa inteligencia cual una revelación milagrera. Según ocurre en los rancios santorales. recuérdanse alli sus dias de aprendizajc en cierlo colegio malagueño de Miraflores del Palo. tal la anunciación de un alba para la cultura. ¡Cómo aprendió su latin y su griego, arduas disciplinas. enitre doctas solanas, en esa edad en que los boquirrubios sólo se preocupan en urdir bellaquerias detrás de las puerlas, asi lo decia don Luis de Argole y Góngoral

Años de aprendizaje de Fauslo, antes que de Wilhelm Meister; de un Fauslo ayuno aún de su necesario Mefistóleles, se nos ocurren más larde, ya entrado el mozo en su provecta gravedad, los del flamante bachiller que va en busca de su doctorado, portando bajo el brazo aquella primera tesis 
-El Milenario, que tan bien debia cuadrar con su frente preñada de doctos pensamientos.

Corrian aquellos años de triste pesadumbre para la vida española: la guerra de Cuba había liquidado toda la herencia de un siglo y algo insospechado, renuevos vigorosos, hinchaban las sementeras de la cultura. Los primeros libros de Baroja, de Azorin, de Valle Inclán, de Juan Ramón Jiménez andaban ya exibiéndose en las vitrinas, asustando burgueses con sus portadas llamativas y con esos tilulos que eran las únicas ejeculorias de talento, que el Max Nordau de .Degeneración. les concedia a los nuevos.

El primer lustro del nuevo siglo prometia fructuosas cosechas para el futuro. Por aquellos años, verde primavera del espiritu. llegamos a Madrid, cuando aún no se iban del todo los de la generación pasada: Valera con su triste ceguera: Núñez de Arce silencioso en sus laureles: Echegaray cubierto de condecoraciones: Pérez Galdós anciano. concibiendo sus postreros Episodios: Menéndez y Pelayo encerrado en su biblioleca; doña Emilia Pardo Bazán recibiendo los homenajes de su elerna y agradecida Galicia. Lo nuevo. la revolución, llamábase entonces, a pesar de ciertos entusiasmos del autor de Pepita Jiménez, y de ciertas complacencias del agudo Clarín. Rubén Dario con sus sProsas Profanas, : Baroja. el de .Vidas Sombrias;: el Unamuno de enn torno al casticismos: Azorin, el de - Charivarí y esoledadess: simples revolucionarios ideológicos en sus comienzos: Valle Inclán con sus .Sonatass: Juan Ramón Jiménez, aulor de Ninfeas:: los Machado, muy caslizo Antonio, muy verlaineano Manuel.

Dario. maestro de tal hora y entre esa generación. lírico mayor que bien conocía los secretos de la orquestación wagneriana, fué el primero que descubrió a América la nueva España; a través del puente de plata que le lendieron sus crónicas, pasaron uno a uno los nombres insospechados, que eran las banderas del arle nuevo peninsular. Antes que él sölo Clarín, que les habia franqueado las puertas de los Pirineos a Zola, Baudelaire, Carlyle, y Valera, inquielo de cosmopolitismo, habian 
presentido la eclosión de esa primavera, que iba a florecer plenamenle después de su muerte.

Era la hora del simbolismo. el llamado de Verlaine y de Lutecia, a pesar de Moréas, sepulturero oficial de los cenáculos de Mallarmé. Sin embargo, el cuerno de Tanhäuser ganaba lambién sus adeplos, invilando al viaje que había hecho antes Sanz del Río en busca de Krause. Educadores, esludiosos. oponentes a futuras cáledras de filosofia. iban en la peregrinación necesaria que alraían los centros universitarios ludescos. renovando las dilecciones gralas a Giner. Salmerón, Azcárale y Castro.

Flamante en sus devociones especulativas, empollado en las enseñanzas de la Universidad Central, en pleno ambiente krausista. Ortega y Gasset partió a Alemania para completar sus estudios de filosofia: estuvo en Leipzig. Berlin. Marburgo. Asi como Jena tenia las enseñanzas de Eucken, Leipzig la soberbia cátedra de Wundt. Marburgo atraía a todos los kantianos. Alli estaba Cohen, expositor insuperable de las doctrinas del maestro de la . Critica de la Razón Prácticas.

Años melódicamente disciplinados en el ejercicio de la filosofia critica; de absoluta consagración al estudio, que el joven universitario iba a aprovechar muy bien, antes de regresar a Madrid. Kant preside en su. formación intelectual durante esos dos lustros, como no sin cierta ironía lo iba a recordar más tarde. en el homenaje al maestro: Durante diez años he vivido dentro del pensamiento kantiano: lo he respirado como una atmósfera y ha sido a la vez mi casa y mi prisión. Yo dudo mucho que quien no haya hecho cosa parecida pueda ver con claridad el sentido de nuestro tiempo. En la obra de Kant están contenidos los secretos decisivos de la época moderna, sus virtudes y sus limitaciones.? Sin embargo. después de haber vivido en esa casa y en esa prisión, renegando de lodo espiritu misoneisla, se complacia en haber abandonado la filosofia kantiana, siéndole grato en cambio volver a visitarla. como se va en día de fiesta al jardin zoológico para ver la girafa.

Siempre fué excelente escuela para el carácter y el estudio la 
universidad alemana, en cuyo seno la influencia modeladora del maestro y del libro se traduce en el mejor estimulo mental; y sobre todo esa universidad del siglo actual. que ha sido la grande renovadora en la filosofía y en las ciencias, en los momentos en que hacian crisis total las escuelas positivas. Era aquella, pues, una hora harlo propicia para la curiosidad de un espiritu tan bien dotado como el del joven universitario español: el movimiento criticista nacido después de Cohen, de Wundt, de Eucken, cuando aún no apuntaba la sociología spengleriana, iba a influir decisivamente sobre Ortega y Gasset. Las lecciones de Scheler y la critica del psicologismo de Hüsserl. le sorprenden en el momento necesario en que pueden decidir una influencia directiva sobre su concepción de la realidad: la verdad, lo real. el Universo, la vida-como querais llamarlo-se quiebra en facetas innumerables, en vertientes sin cuento. cada una de las cuales da hacia un individuos. Hay en ese momento, detrás del kantiano formado en las lecciones del anciano Cohen, un despunte de la tendencia que luego va ser directriz en toda su ideologia: el perspectivismo. Ya lo va a probar, más tarde, cuando afirme que es preciso abrirse a la convicción de que el ser definitivo del mundo, no es maleria ni alma, ni cosa alguna determinada, sino una perspectiva.

Es el momento especlacular en que se ha liquidado un sistema, el de todo un siglo, que fué el de la filosofia positivista: los últimos cincuenta años de la pasada centuria sólo contribuyeron a cancelar toda noción medianamente clara de filosofia: - Después del siglo X, dirá Orlega y Gasset al presentar el libro de Voländer, no ha habido etapa hislórica en que Europa poseyese menos sensibilidad y saber filosóficos que en los cincuenta últimos años del siglo XIX. Esto ha producido el caos mental que ahora, con sorpresa, encuentra a Europa dentro de si. $\mathrm{Y}$ es que la cultura de los especialistas crea una forma especifica de incultura más grande que olra alguna.. Pero el siglo XX ha vuelto por la buena tradición, procurando concebir en su esencia pura la verdad, buscándola en su sentido absoluto. La.sensibilidad perceptiva nos permite crear conceptos, de manera 
que la realidad de las cosas que creamos, está determinada al sujelo que la percibe. El problema de la realidad en sí, de la realidad absolula, será siempre una incógnita impenetrable.

Toda perspectiva que se proyecte hacia la realidad la sorprende bajo un aspecto cambiante. en alguna de sus facetas. en su relatividad natural. ¿Acaso el propio Einstein no ha probado este aspecto neto del perspectivismo? La realidad no puede ser absoluta, pero sí el conocimiento que podemos llegar a tener de ella: vale decir. la realidad está en las cosas que tienen sus diversos aspectos. su perspeclivismo: lo real se proyecta en facetas diversas hacia el individuo.

Más dichoso que Ulises, que no añoraba su Itaca después de escuchar el canto de las sirenas, pudo regresar a esa España en la hora oportuna Ortega y Gasset. a la España de la pre guerra mundial, allá por los comienzos del tercer lustro del siglo. Nada fundamental había cambiado en la vida intelectual de la peninsula: la politica. las letras, los hombres. Como Descartes después de su viaje a Alemania y a Holanda, volvia Orlega a su Madrid, animado por un soplo de noble primavera.

Muerto Salmerón, gana las oposiciones a la cátedra de metafisica en la Universidad Central y ese es el punto de partida que abre la más digna de las etapas en la vida cultural española de este último tiempo. Un poco solitario, armado con todas las disciplinas de la sabiduria, con una dignísima tradición burguesa tras él (ese burguesismo en el cual va a repudiar más tarde el sentido de la democracia: cel hombre moderno es burgués.. dirá en su ensayo sobre Kant): muy superior a los otros por los dones de su cultura excepcional; aprendiz de filósofo donde la filosolía no se daba como flor en campos propicios: artista de gustos nuevos, dueño de un estilo elegante. flexible, modernísimo, rico en ideas, así el árbol que ha recogido todo el sabor de una tierra opima, era un poco el esperado. el genio de su hora en un medio propicio.

No conoció la época del aprendizaje porque nació flamante y completo de las aulas tudescas, como el simbolo de la diosa en la mente jupiteresca. Antes de escribir su primer libro, gozaba 
de la repulación de joven maestro. Era el más europeo de los españoles y. al tornar a Madrid. pudo sentirse el más español de los europeos: Regeneración es inseparable de europeización, pudo escribir por ese entonces, soñando como Clarín en franquear las ventanas de los Pirineos.

Sus primeros libros suenan a epifania: aquellas -Meditaciones del Quijotes, que nada dicen del hidalgo pero lanto de su espiritu: los ensayos sobre Renan y otros escritores. ya españoles, ya extranjeros; los dos volúmenes iniciales de eEl espectador, revelaban a un artista singular, en quien el pensador y el escrilor de sensibilidad refinada, movian a colocarle entre esos doce pares del intelecto europeo que recordaba Curtius.

Después de las controversias por el arle nuevo, reñidas por las generaciones de Rubén Dario y Valle Inclán, el advenimiento de Ortega y Gasset traía un aspecto de novedad harto más plausible, capaz de hacer olvidar a aquél. como bien pronto iba a ocurrir. Orlega no reclamaba el siglo dieciocho versallesco, ni las galanterías de Casanova: su pensamiento y su estilo eran bien modernos, sueltos, fáciles, actuales. Comenzaban a tener la gracia del cubismo. la soltura del baile ruso, un poco del Stravinski de hace diez años, y la audacia de la física einsteineana. De tal manera lo mejor en su arle fluye en facilidad, en virtuosismo: juega con las ideas como con hojas afiladas y huidizas; baraja las metáloras y a veces se nos ocurre un sofista empeñado en un fácil acertijo de probanzas y aciertos. Prestidigita como ninguno, en un ilusionismo que a veces se encarga en desvanecer con una afirmación. Por lo demás él mismo ha dicho que el arke es un juego, un simple juego: A Ahora que se irá viendo hasla que punto el arle no es cosa seria, sino más bien un fino juego exento de patetismo y solemnidad.

Para él parecía no tener secretos la cultura, porque tan bien puntualizaba la valorización de las doctrinas de Kant como comentaba a Spengler y a Proust o revelaba a Frobenius y a Simmel, ese Simmel cuya influencia no deja de orientar un momento de su evolución intelectual, aquella de las Meditaciones 
del marco. Sin embargo, cosmopolita, supo no dejar de ser español, vale decir un peninsular que, estando tan cerca de Europa, no queria olvidar el preeuropeísmo africano que señaló Keyserling. No es el sentido de la barbaric. algo de esa africanización de los sentimientos que un dia le reprochó a Unamuno. sino lo que Frobenius encontró en las culturas desaparecidas como carácter y sabor autóctonos. En lo cual él buscaba ese algo característico de la hora actual, que se desvive por las culturas humanas más remolas. llegando a pensar lo que Schulten rastreaba en Tartessos y Schiemann en Troya. Asi. lo que intentaban Frobenius o Spengler fué un excelente trampolin para las nuevas posibilidades ideológicas de Ortega y Gasset. España debía también ser ubicada como cada grupo en el sitio preciso que le corresponde en la historia. previa reconstrucción de la estructura que ha tenido en su evolución. $Y$ en este sentido, al justipreciar o al afirmar, sus palabras se revestian de un tono autoritario, perfectamente nietzscheano: el espíritu lógico lo impulsaba muy lejos. España no ha tenido grandeza como nación, ni grandeza como cultura, porque purga en ello su defecto de origen, de constitución: no en balde no floreció en ella el leudalismo, al que deben otras naciones lo mejor de su grandeza. Además, en el reparto de las invasiones germánicas a España le tocaron en suerte los visigodos y no los francos. cuando los francos eran los germanos puros. los buenos, los nobles. Es decir. España pudo disfrutar de la herencia pensante que perdió con el visigodo, quedándole lan sólo el visualismo latino, que iba a determinar su carácter secular. En ese dualismo llevó la peor parte: el latino sensorial y el germano meditativo. ¿¿Qué es meditar comparado con ver?. Hay cumbres en el pensamiento renacentista como Descartes, en quienes se pueden reconocer todas las virtudes salvo la claridad. En cambio Leibnitz o Kant o Hegel, son difíciles, pero son claros como una mañana de primavera. Giordano Bruno y Descartes, tal vez no sean del mismo modo dificiles, pero, en cambio, son confusos.. Una figura representativa del intelecto mediterráneo es Juan Bautista Vico: no puede negársele genio ideológico, pero quien haya entrado 
por su obra, aprende de cerca lo que es un caoss. Y mientras los pueblos de la Europa meridional no han hecho sino contribuir a desvirluar la débil herencia latina, el alma alemana encierra la más elevada interprelación de la cultura europea, cuya clásica aparición hallamos en Atenas. Gracias a Alemania tenemos alguna sospecha de lo que Grecia lué: no nosotros, ellos con su proverbial pesadez, con su lentilud, con su cerveza, con su castidad.

Arduo problema por resolver sería esle del latinismo y del germanismo que, en cierto modo, planteó un olvidado sociólogo francés, con razones no exentas de puerilidad, hace algunos años, cuando la moda anglómana buscaba en Paris una correspondencia a las ententes politicas. Sin embargo. Ortega, en acto de terminanle profetismo spengleriano, sanciona el carácter inferior del mediterráneo peninsular, de suyo enemigo de toda innovación. entregado a un inconsecuente misoneismo: aceptar lo nuevo es humillarse: supone reconocer que no se es perfecto: -Al español castizo loda innovación le parece francamenle una ofensa personals.

Acaso una razón tradicional explica la peor enfermedad que padece España: el orgullo que imposibilita ese hecho primario social capaz de fundar una organización en dirigidos y directores. Lo cual supone, en unos cierta facilidad para dejarse dirigir y en otros capacidad para dirigir: edonde no hay una minoria que actúa sobre una masa colectiva, y una masa que sabe aceplar el influjo de una minoria, no hay sociedad, o se está muy cerca de que no la hayas.

La objeción fluiria fácil contra cse supuesto dominio de las masas en un pais donde el pueblo vive yerto bajo la inercia. dispuesto a aceptar cualquiera autoridad. desde la de una clase privilegiada explotadora. hasta la de un rey sin autoridad o de cualquier mandonzuelo audaz.

Antidemócrata, por aquello de lo plebeyo, Ortega cree sentir en su España la lirania insufrible del espíritu bajo: clenemos que agradecer el adviento de tan enojosa monarquía al triunfo de la democracia. Al amparo de esta noble idea se ha deslizado 
en la conciencia pública la perversa afirmación de lodo lo bajo y ruin.. ICómo teme, cómo repudia esa democracia exasperada en religión, en arte. en el pensamiento, en el corazón y en las costumbres! Bien por el filósofo que vive en su torre $y$, de tarde en larde. se asoma a sentir el vaho ya frio de la vida. que sube hasta él. mientras abajo está el dolor que se debate. porque sobre él pesa una injusticia secular. El filósofo querria enmendar con caridad lo que la caridad no podrá sino violenlar. Ese sentimiento de la democracia que Orlega lustiga, se le aparece como una degeneración de los corazones, cual un error: el caso de un hombre que veia pasar una marquesa en su carroza, en 1789, y se exlasiaba en la conlemplación de ese lujo y de esa distinción, era el caso de uno de tantos pobres de espiritu incapaz de justipreciar el sentido de la más abyecta de las supervivencias expoliadoras. ¿Cómo gozar de una belleza que sabemos está amasada con el sacrificio, a costa de quién sabe cuántas trislezas anónimas? Pero ¿sería preciso, una vez más. para explicarnos ese 1789 justiciero. volver a los primeros volúmenes de Taine, quien al fin y al cabo también algo tuvo de parte interesada? ¿Cómo pedirle al misero atorrante que se alegre de la ajena magnificencia mientras ahoga sus angustias y sus hambres y mientras su sensibilidad apenas le permite darse cuenta de sus simples apetitos? Orlega, hombre de universidades, lipo del intelectual frío, egoísta, incapaz de abnegación cordial, no puede sino vivir lejos del hervor vital. olvidándose cada dia más de las miserias de esa España suya, que se empeña en ignorar con soberbia, con la soberbia del que olvida demasiado su medio burgués en peregrina succión hacia las clases privilegiadas.

Mas nos llevaria muy lejos la fuga de estas glosas. si quisiéramos puntualizar el discurrir elegante. Ileno de gracia tortuosa. de este pensador, tan ágil, tan insconstante. Su obra resume la expresión más nueva en las letras actuales: el espiritu de sintesis, situado en un perspectivismo constante. En la filosofia encuentra la disciplina ideal de su entendimiento; es decir. la filosofia como reacción contra lo erudito, la noticia, la anécdota. Lo historiográfico, el dato, son la regresión a la filologia, como si la quimica 
tornara a la alquimia. La filosofía, pura sintesis, excluye cuanto queda en su extraradio: es como una depuración completa de una buena alimentación, en la que lo asimilable se convierte en el vigor esencial.

Después de Alemania, de Kant, de Cohen, de su severa cáledra consagrada a la melafisica: después lambién de su viaje a la Argentina, viaje en el cual América supo sonreirle como una sirena ocultándole sus dolores y sus miserias, ni más ni menos que al Budha adolescente. Ortega ha sentido renovarse el milagro de Fausto, ese que pudo sentir Nietzsche antes de Sils Maria: - Era esto la vida? [Bueno, venga otra vez! ,

Nunca es tarde, por lo demás, para que un filósofo de cuarenta años descubra la vida: tal vez la hora de su dharma luvo la culpa del retardo: Testigo soy, un testigo de la gran maravilla que es el mundo y los seres en el mundo. En adelante. siempre ya, marchará al frente del espectáculo. marcando el paso. en su liviana actitud deportiva, tal el hierofante que inicia la caravana de las novedades.

Como Simmel puede cavilar que la nada no es ya algo frivolo y que el único castigo debe pesar sobre los que se quedan en rezago. No importa cambiar, no importa rectificarse, porque quien se apresura olvida lo que tras él deja. Ahora el filósofo comienza a tener algo del snob. pero del más inteligente de los snobs, que frecuenta el salón donde el circulo aristocrático teje sus homenajes de amor y galanteria. como el Proust que siempre marcaba la hora del lado de Swann: ahora el joven maestro comienza a ejercer un magisterio de avanzada espiritual, asi el Cocteau no converso aún; ahora el profesor. que ya no busca solamente en Aristóteles las lecciones de la politica, loca la más grave de las campanas en los funerales de Maura.

Huyendo del más digno de los sentires de sus contemporáneos se aleja, con un frivolo desdén, de cuantos caminos pueden acercarle a lo humano, al dolor humilde. a todo sentimiento de justicia. Sordo, ciego, mudo. en una hora de grandes angustias morales, se desentiende de cuantos quisieran verle entre 
cllos, como Pascal o Nielzsche cuando pedian un hombre, solamente un hombre.

Mas, descorramos un instanle la cortina...

\section{UNA CONVERSACIÓN DE CORTESIA}

Aguardamos en la amplia sala de recibo de un tercer piso en la calle Serrano, ancha y soleada vía madrileña. Un piano: algunos muebles; grandes reproducciones colgadas de los muros. El caballero de la mano en el pecho y la Gioconda: dos estanles contentivos de muchos libros, bien encuadernados. ¿Qué obras son éstas? Filósofos, filósolos, filósofos: volúmenes de Hegel, de Platón, de Kant, de Schopenhauer; la sKritische Gänge, de Vischer; el (Tage-bücher, de Hebbel: algunos volúmenes de Anatole France; uno que otro libro español o hispano americano, sin abrir y, luego. filósolos; más filósofos: Fichte, Cohen, Aristóteles.

Aguardamos: cinco minutos, diez minutos. Una carta gentil de Gregorio Marañón nos ha precedido. ¿Obrará el milagro del sésamo ábrele? Un escritor. pensamos, suele ser victima de algunas distraccioncs. También tiene su importancia saber hacerse esperar.

De pronto se abre la puerta. Es un instante patético. Ortega y Gasset nos brinda asiento. Palabras, palabras perdidas: excusas, adjetivos banales. ¿De qué se puede hablar en una helada, incómoda, grolesca visita de eliqueta? Quisiéramos marcharnos. estar lejos, rehuir aquella conversación forzada, sin intimidad.

El rostro de Ortega parece algo descompueslo: cetrino, con aire de latiga y de muerte. Sus pupilas, descoloridas, son muy expresivas. Su voz. pastosa, de lono hondo, caliente, vibra como un diapasón. Mientras María, nuestra compañera, le martiriza con una pose fotográfica, le observamus atentamente: es un hombre pequeño. de cuerpo enjuto. cuya cabeza es fuerle. grande, enorme: una cabeza que parece haber malogrado el desarrollo de un cuerpo fino, incapaz de mantenerla erguida. Bien se comprende que el tronco se agostó en la penumbra de 
las bibliolecas, doblado sobre los libros, lejos del sol, de lodo estimulo físico. mientras la bóveda de ese cráneo revestia la arquitectura de una cúpula.

Aún le observamos: correctamente vestido, su americana es de impecable corte. En los puños de la camisa luce dos bonitos gemelos: rubies y brillantes. Su corbata se anuda y ciñe con gracia. Casi nos atreveriamos a decir que viste con'delicada y Tácil elegancia.

Ya la placa está impresionada. Nuevamente queremos hilvanar la charla. Preguntas, vagas respuestas, silencios, silencios. El más modesto de los filósofos tudescos, que nios observa desde las estanterias aprisionado en su volumen, podría exclamar: Ein Engel schwet über uns... de tal manera callamos, callamos inútilmente.

Algo querriamos saber del volumen cuarto de .El especfadors: Orlega nos responde que estará enteramente consagrado a un estudio sobre Proust. Pensamos en las milagrosas páginas publicadas en la Nouvelle Revue Française y en cierla conferencia leida en el Instituto Francés de Madrid. Ortegza nos asegura que está totalmente rehecho, porque se lo ha pedido Gallimard para darlo en sus ediciones.

Le pregunlamos por el volumen, anunciado en sus anteriores libros, sobre la Estimativa o teoría de los valores.

- No he hecho casi nada: apenas si tengo tiempo y acomodo para escribir lo más ligero de mi obra. lo que no me interesa.

Todavia cabe hablar de libros, de escritores recientes, de las ediciones de su revista. Muchos de los volúmenes publicados apenas si le preocupan: lo mejor está por ser dado a la estampa. ¿Bernard Shaw y su discutida Santa Juana: Hauptmann y su Isla de las Damas, escasamente prodigiosa? Sonrie vagamente y nos dice, sin concederle imporlancia al ligero juicio incidental:

- Hauptmann es ya un Padre de la Iglesia: tiene toda la pesadez plúmbea de las malas cosas alemanas. No es su lite- 
ratura lo mejor que pueda mostrar Alemania, sino la producción de tres o cuatro de sus cabezas más fuertes.

¡Pobre Haupimann, el Haupimann que escribió ^Almas solitarias». sLos lejedores, y cLa campana sumergida-! Pero. en cambio, hay tres o cuatro cabezas fuertes en la patria de Goethe: ¿Hüsserl, Scheler, Simmel, Spengler, Keyserling. Otto? cavilamos in pelto.

Como Proust es santo de su devoción (¿podria olvidarse aquel ensayo magnifico de Ortega publicado en el número especial que la Nouvelle Revue Française le consagró al aulor de aAlbertina desaparecida.?) y como está presente el eco de cierto arliculo sobre la influencia que ha cjercido entre los nuevos escrilores, le insinuamos otra pregunla, buscando acaso la manera de encontrar un escritor de su agrado. Entonces se habla de Giraudoux, de Morand, de Girard... Pierre Girard. pensamos con alegria. evocando su leclura más reciente, ese delicioso sord Algernon.

A nuestra pregunta sobre la grácil novelita, que recuerda un género de humorismo cmotivo digno de Chaplin. seçún lo observaba accrfadamente Edmond Jaloux, replica desdeñosamente Ortega:

-Fernando Vela me dijo que no valia gran cosa. Es el mismo procedimiento. que está bien en un primer libro, pero que no debe repelirse. Después de .Yuna. Felipe y el Almirantes no se puede volver a lo mismo.

En vano Maria, devota e irreductible girardisiana, protesta; clama porque no les ha gustado stord Algernons, que en una próxima nola de la .Revista de Occidentes va a analizar con helada indiferencia el propio Vela. María insiste ante Orlega para que lea esa novela, Ian nueva, tan original, tan superior a lodo lo del propio Giraudoux, con quien se suele comparar. para disminuirlo, a Pierre Girard.

Ortega escucha, en actitud inexpresiva, con una leve sonrisa en los labios. Pero no dice nada: calla, calla y apura uno tras otro sus gruesos pitillos. 
De pronto se abre una puerta. Asoma una criada. Musita algo. Comprendemos...

Afuera, en la calle Serrano. el sol, un sol de estio, desmiente las inclemencias del invierno madrileño.

Con su kodak en la mano. algo mal humorada. Maria mira sin mirar a lo lejos, desde el fondo de sus pupilas ausentes.

\section{COSAS DE BAROJA QUE ESCUCHA AZORIN}

Han Iranscurrido varios dias. Rueda la vida literaria como un pesado carro, sin otra alternativa que la rara aparición de un libro (.Cinco minutos de silencios, de Eugenio D.Ors: „Don Juan, don Quijote y la Celestina», de Ramiro de Maeztu) o de algún buen articulo en El Sol. Las tertulias se recluyen en tal - cual café: en la Granja de El Henar, donde cada noche Valle Inclán preside algún grupo afecto o en la botelleria de. Pombo, que recibe más alegre que nunca a Ramón Gómez de la Serna, a su regreso de Portugal. Pero cy Baroja, y Pérez de Ayala, y Ortega y Gasset y Azorín y Araquistain y Diez Canedo y Eugenio D'Ors? Sólo de tarde en tarde los vemos en un té. en alguna comida, en un estreno. Todos viven intimamente. alejados del bullicio que vibra y pasa, escuchando desde lejos el estrépito de su cascabel.

Sin embargo, hemos vuelto a encontrar con frecuencia al autor de las -Meditaciones del Quijotes en la Revista de Occidente; en un palco del teatro Comedia, para escuchar a Berta Singerman, o en amable ágape con que nos obsequia don $\mathrm{Ni}$ colás María de Urgoiti. Por lo demás Madrid es pequeño y el sol callejero saca al fin a cada cual de su pequeño refugio.

El reposo convivial de este almuerzó. en compañia de Ortega y Gasset y de Azorin, nos ofrece ocasión oportuna a fin de hablar, de hablar sin apremios. La sobremesa es propicia y grata para oir discurrir a tan fino causeur y a tan ágil disociador de las ideas, como es el joven maestro de la nueva España. Azorín, en cambio, es menos locuaz, más tibio y reservado; escucha atento, un poco melancólico y un poco triste. Urgoiti, franco y 
Simples conversaciones con Orlega y Gasset

cordial, es hombre de ideas netas, buen lector, muy liberal en sus ideas y de muy firmes convicciones.

Ortega y Gasset habla brillantemente, como el mejor de los oradores. pero en ese tono menor que tan bien aconsonanta con su voz. Su palabra es cálida. fuerte, juvenil. El momento brinda un asunto propicio: acaba de hundirse el primer minislerio del Directorio y la prensa anuncia la formación de un nuevo Gabinete, constituido por elementos civiles y militares. Urgoiti refiere que la censura le ha objetado en El Sol a Bagaria una caricatura muy intencionada, en la cual aparecian tres sables y seis vainas bajo este título: el nuevo Gobierno. Una sonrisa burlona circula un instante. Nadie cree en la caida inmediata de Primo de Rivera, que acaba de salvarse con habilidad. Azorin dice que todo lo veía llegar, mientras Ortega asegura que no se puede pensar en la posibilidad de que se abran las Cortes. ni en algún cambio hondo que haya de modificar lo que existe en la actualidad. El descaría para España un régimen en el cual pudiera existir mayor concurrencia en lodas las actividades de la vida peninsular: mayor consonancia en el dinamismo de las luerzas creatrices: más estimulo y más libertad en la acción organizadora de las provincias, que hasta ahora. con raras salvedades, se arrastran como un cuerpo muerto.

Pensamos en las páginas elocuentes de España invertebradas y en las de aquella conferencia augural en la vida de esle escritor: Vieja y nueva políticas: pensamos en los recios artículos consagrados por Ortega, en EI Sol, a Maura y la politica. a Maura que renovó el problema planteado por Costa: y pensamos también en aquellas páginas, maduras de porvenir. del malogrado Ganivet cuando, al hablar de Granada, escribia: - La ciudad que pretenda vivir su vida propia, gozar de la libertad de sus movimientos. debe esforzarse por ser de hecho como desea ser considerada por las leyes... Para mi la clave de nuestra politica debe ser el ennoblecimiento de nuestra ciudad. No hay nación seria donde no hay ciudades fuertes.. Con oportuna previsión recordaba el autor del sIdearium español. que le habia tocado vivir en antiguas ciudades libres, que con- 
servaban su liberlad. gozando de la plenitud de sus fuerzas. pues en ellas el ciudadano pensaba primero en su ciudad y despućs en la nación. porque la ciudad era el centro de su pais. el núcleo de una energía vital hacia la que concurria, como en la übe antigua, el esfuerzo sin reservas y sin ambiciones. ¡No habia sentido en vano. muy honda, la impresión de las tradicionales ciudades del norte alemán y no habia sido para él una lectura frivola la de las páginas de Fustel de Coulanges!

pero, como quiera que el tema es ingrato $y$ como Azorin calla, amodorrado acaso por ese discurrir fan ajeno a sus dilecciones y a la suave y plácida digestión que invila a la siesta. Ortega le dice cordialmente:

-Estará usted satisfecho con el éxito de „Doña Inés. .

Azorin asiente con una ligera inclinación de cabeza. Masculla algo y luego un si borroso, de sordina, se escapa de sus labios.

Transcurre un instante denso. Ahora se habla de Baroja. Azorín y Orlega son acaso sus mejores amigos. En aJuventud Egolatria. Baroja recuerda, en cada página, a Azorin, aunque ahora piensa que .Doña Inés, es la obra de un discípulo mediocre del Azorin de otros años, vale decir del Azorín de eLa rula de don Quijotes. Por su parte el autor de sLa voluntad. ha sido el mejor vocero del novelista vasco. En el prólogo de su penúltima obra. Baroja endereza a Ortega sus disquisiciones sobre la novela, que éste ha replicado en cierto modo en los folletones de El Sol. recogidos luego en sa deshumanización del aríe. Además, en uno de los volúmenes de .El Espectador, encontramos unas finas notas sobre algún libro de Baroja. ¿Cómo no pensar, cavilamos, en Menéndez y Pelayo. en Pereda y en Pérez Galdós, amigos, amigos siempre, apesar de sus ideas tan antagónicas? Claro don de la amistad que no excluye los dictados de la justicia critica.

Ortega recuerda con entrañable cariño al autor de Inventos y mistificaciones de Silvestre Paradox.. Habla del novelista vasco con entusiasmo cordial que nunca hemos encontrado en sus palabras para otro escritor español. 
- Baroja es lo más interesante, dice. No hay nada en España comparable a èl. No sólo sus libros sino que su persona merecerian un estudio especial. iY qué buen humor tiene como compañero de viajel Recuerdo una larga excursión que hicimos con él. Iba con nosotros el joven diplomáfico $X$, que poco después se volvió loco. Padecia éste de una admiración maniática por Goethe, hasta el punto que nunca abandonaba las .Conversaciones, de Aeckermann... Ese dia habiamos hecho un recorrido largo, muy penoso. Los caminos eran pésimos y la diligencia nos habia maltratado mâs de lo conveniente. Estábamos rendidos de faliga, de hambre, de sueño y con un frío polar. El joven diplomático no perdia, sin embargo, cabo para continuar disertando de Goethe, a pesar de nuestro desfallecimiento. En la posada le tocó en suerte dormir en el mismo aposento que Baroja.... Muy entrada la noche, tarde, muy tarde. sentimos la algarada que provocaba una disputa violenta en el cuarlo vecino de nuestros compañeros de viaje. ¿Qué habia ocurrido? Pues que el joven diplomático continuaba dándole la lata sobre Goethe a Baroja y éste habia terminado por perder la paçiencia, amenazándole con arrojarle del cuarlo junto con el autor de Faustos. Aeckermann y todos sus admiradores....

Azorin rie maliciosamente, conteniendo los hipos que parecen impedirle soltar una carcajada.

-Baroja es delicioso, prosigue Orlega. Figúrense usledes que, en las excursiones que soliamos hacer para visitar iglesias. no conseguia que se quitara la boina por lemor a los constipados. A veces, cuando la proximidad de algún altar imponia la necesidad de descubrirse, reemplazaba la boina con un enorme pañuelo de yerbas. que dejaba a cubierto la calvicie.

Con entrañable afecto, que no atenúa ninguna reserva. le place a Ortega ir refiriendo tales anécdotas inocentes, que son como las pinceladas entonadoras de este relralo vivisimo de Baroja. del Baroja que nada tiene del hombre de acción, vale decir de su Avinareta.

- Es persona muy fina y el más amable y espiritual de los 
conversadores en sociedad. ICómo logra ganarse el interés y las simpalias de las mujeres!

Pensamos, pensamos. sin atinar a conciliar anteriores informaciones que muestran al novelista adusto. misógino empedernido, en este Baroja doblegado a la tirania social, convertido en causeur de salón, muy bien acomodado entre finas, pulcras y bonitas damas. ¡Cuándo su amigo lo dice!

-Un dia, recuerda aún Ortega, la madre de Baroja le convenció sobre la necesidad de mandarse hacer un smoking. Y. a vuelta de muchos rodeos. Pio doblegó su voluntad ante aquella necesidad. entregándose en manos de un sastre. Arlista en su oficio éste, observó la estampa de Baroja y. no satisfecho acaso con su obesidad. descubrió que el novelista abultaba la barriga con amplia faja de muchas vueltas. El smoking. prenda que debe sentar al justo, pensó, va a resultar deforme. Insinuóle entonces a Baroja la necesidad de dejarse tomar las medidas sin el envollorio, súplica inútil porque éste se negó rolundamente. debiendo el sastre corlarle la ropa según lo exigia la proluberancia de la faja de marras...

Ahora si que Azorin rie, rie de buena gana, casi estrepilosamente, aunque sea a costa de su amigo el novelista, creador de las graciosas peripecias de Silvestre Paradox.

Tarde a la tarde, mientras la lluvia rompe sus agujas de cristal contra los vidrios de nuestra ventana, interrogamos a las páginas de .El especlador. lo que Orlega piensa de la obra de Azorín y de la obra de Baroja.

.En Azorín no hay nada solemne, escribe, majestuoso, altisonante. Su arle se insinúa hasta aquel estrato profundo de nuestro ánimo, donde habilan estas menudas emociones tornasoladas... Por una genial inversión de la perspectiva, lo minúsculo, lo atómico, ocupa el primer rango en su panorama, y lo grande, lo monumental, queda reducido a un breve ornamentos. Luego observa Orlega que Azorín deja pasar ante su faz casi inerle lodo cuanto pretende representar primeros papeles en la escena de la vida: .De pronto notamos un breve temblor en sus labios juntos; una suave iluminación en su pupila; ade- 
lanta la mano, señala con el indice a un punto del paisaje humano. Seguimos la indicación y hallamos... esto: un pueblecitoun nombre desconocido u olvidado - un detalle del cuadro famoso que soliamos desapercibir, una frase vivida que naufragaba en la prosa vana de un libro. Como con unas pinzas sujela Azorin ese mínimo hecho humano. lo destaca en primer término sobre el fondo gigante de la vida y lo hace reverberar al sols. Azorin se le ocurre a Orlega un sensitivo de la hisloria: es decir. todo lo contrario de un filósofo de la historia. Su obra, opuesta a la de Baroja, etiene de común con ella esa lontananza gemebunda. ese contrapunto palético y latente que he llamado trémolo melafísicos.

Baroja es para el autor de .El Espectadors la más firme. casi valdría decir una de sus raras devociones españolas. Es preciso recordar que en la dedicaloria de su ensayo sobre el novelista, a esos muchachos díscolos e independientes que en algún rincón de la vida provinciana viven en constante irritación contra la atmósfera circundante, situaba el caso de Baroja como el de un hombre libre y puro, eque no quiere servir a nadie ni pedir a nadie nadas.

Observa Orlega que el novelista ha hecho de su obra una especie de asilo nocturno donde únicamente se encuentran vagabundos: aquellos hombres de condición inquieta y despegada. eque no echan raices ni en una tierra ni en un oficio, sino que van rodando de pucblo en pueblo y de menester en menester. empujados por sus fugaces corazoness. Son creaturas errabundas e indóciles. que no quieren disolver sus instintos en las formas convencionales de vida que la sociedad exige. Asi buscando esos seres vagabundos, al margen de la sociedad. esas vidas que son un fracaso práctico, ha dado con las verdaderas almas victoriosas, las únicas que se rebelan contra la vida burguesa, contra el burguesismo odioso que, ha desalojado del mundo todo lo exquisito, lo socialmente ineficaz. Así, pues, el efecto que haya de producir la lectura de Baroja, suele ser de indignación porque él eno se contenta con discrepar en más o menos puntos del sistema de lugares comunes y opiniones con- 
vencionales, sino que hace de la protesta contra el modo de pensar y sentir convencionalmente nervio de su producción.. Sin reparos dice Ortega que en esla ansia de sinceridad y leallad consigo mismo no conoce nada en España y fuera de ella comparable con el novelista: Baroja es el caso extrañísimo. en la esfera de mi experiencia único. de un hombre constituido exclusivamente por ese fondo insobornable y exenlo por completo del yo convencional que suele envolverlos. Como Stendhal podría decir el autor de . César o Nadas: cuando miento me aburro.

\section{LAS ARGENTINAS... LAS MUJERES, EL AMOR}

Llueve, llueve sin quebranto. Se deshace en copioso aguacero la cenicienta larde madrileña. ¿Qué hacer, recluidos en la odiosa soledad de un cuarto de hotel? Bienvenida sea la esquela, con dos letras de Orlega, que nos invila a tomar el té en su casa. Acudimos con Maria. al finalizar la tarde, cuando ya las luces del crepúsculo se han deshecho en la noche anticipada de eslos dias de Diciembre.

Por segunda vez nos encontramos en la sala amplia donde los libros, graves volúmenes de helada filosofia, se alinean en sus ringlas, acurrucados en las estanterias. Nos reciben Rosa Orlega y su esposo. Ella fina, amable, serena. Sus grandes ojos claros y sus palabras suaves, parecen llenar esa casa que el primer dia se nos ocurrió fría y hostil. Maria quiere conocer a sus hijos y, uno tras otro, desfilan los tres muchachuelos: e! mayor un garzón fuerte, corpulento, de cabellera rebelde, de facciones loscas: el segundo más parecido a su madre, sano. encendido: y. el tercero, una chica bonila como una muñeca, de pelo castaño y limpios ojos azules.

Una taza de té suele ser el mejor propósito para hilvanar una charla cordial. Y es asi como aquella tarde decembrina. el ambiente hogareño parece haber ido fundiendo poco a poco el hielo de las primeras pláticas.

Ortega eslá de un humor excelente. Maria recuerda la visita 
Simples conversaciones con Ortega y Gasset

inicial que le hiciéramos, aguardando en la misma sala en que ahora nos recibe. De pronto, y no sin cierto rencor. le dice:

-Ese dia estuvo usted perfectamente impertinente...

Orlega se rie de buena gana y le responde:

- INo ignoraba que usted me tenia por un perfecto salvajel Si no me equivoco, se lo manifestó a mi mujer, tal vez guardándome el infundado rencor de aquella primera visita. No desmiente asi la rebeldia araucana para juzgarme. Tal vez ignoran ustedes que esa tarde me encontraba enfermo y que estuve a punto de no recibirle, apesar de la carta de Marañón. Por lo demás; yo sólo inicio las amistades después de la cuarta conversación, antes no...

Rosa sonrie, mientras ofrece un bollo o un confite.

No le ha hecho gracia a Maria la referencia araucana y. junto con reprochárselo a Orlega, éste le dice:

- No se enfade usted porque es el grano de sal necesario a su lipo interesante. $Y$ el tipo siempre se toma de la tierra, no hay más que observar. Casualmente en $A . B$. C, de ayer se publicaba una folografia de cierto congreso de sufragistas australianas, entre las que se adviertèn algunas fisonomias caracteristicas de inglesas que, habiendo vivido en Sydney o Melbourne, han tomado el sello de la tierra, mostrando frentes abultadas. propias de ese desarrollo excesivo que impone la necesidad de proteger la vista contra las irradiaciones de un sol fuerte. ¿No se ha fijado usted cómo se parecen el hombre y el ciervo en el Japón? Y el gato de la China cacaso no tiene hasta los ojos oblicuos?

Ortega es un hombre de buen humor: de excelente humor a toda prueba. Irreduclible sofista y ágil improvisador. crea y recrea en todo inslante. ¿Qué son las ideas sino blandas y dóciles migajas que toman las formas que sus dedos quieran imprimirles?

La charla se enreda en cosas pueriles: se habla de todo y de nada; apuntan los nombres de dos mujeres de América: llegan pronto a cuento los libros. los libros más recientes. María recuerda La prodigiosa isla de las damas.. la novela de 
Hauptmann, que acaba de publicar la Revista de Occidente: dice que no puede tolerar siquiera veinte páginas de su lectura y Ortega confirma esa impresión asegurando que tampoco consiguió leerla. Deseariamos preguntarle ¿por qué la publicó enlonces?, cuando él. presintiendo acaso la interrogación, agrega:

- Es necesario darles algunos libros a las mujeres...

Gracias, por lo que a mi me loca. le responde María.

Y Rosa, entretanto, sonrie, sonrie. Ortega apunta:

- En cambio me vindicaré con otro libro para ustedes, que aparecerá en pocos dias más: son las .Carlas biológicas a las damas, de Ücxkull, una obra muy clara y muy sencilla.

Aún el tema de los libros parece propicio. Asegura Orlega que no está satisfecho de cuanto ha edilado hasta ahora la Revista de Occidente, a pesar que algunos de los volúmenes. como so santo, de Otto, merecen ser leídos atentamente.

- Los . Cuentos de un soñador , de Lord Dunsanny zle agradan a usted?. le preguntamos.

-Es un libro soporifero, subraya María.

-Yo no lo pude leer, exclama Rosa.

- Si, tal vez, contesta Orlega. Piensen ustedes que ese escritor interesa mucho en Inglaterra... Y el libro de Victoria Ocampo cles gustó?

- Mucho, responde Maria.

Y Orlega puntualiza esa afirmación diciendo que ese libro eslá bien: que eslá hecho en gris, con una fina agudeza lemenina y que en breve se va a reimprimir porque ya se agotó.

Victoria Ocampo cuenta con buenos y fieles amigos en España. Recordamos haber visto a Ricardo Bacza ocupado en traducir, con devolo interés de artista, una reciente comedia dramática suya, que va a publicar la Revista de Occidente. Es preciso no olvidar que la aulora ¿De Francesca a Bealriz. escribe un perfeclo francés. la lengua que aprendió de niña mejor que la propia. Entre los libros cabe la mesa de trabajo, en casa de Jacinto Grau y de Baeza, el retrato de Victoria Ocampo está como un recuerdo patente y patético de la más devola 
Simples conversaciones con Ortega y Gasset

amistad. Nunca tuvo la Argentina embajadora espiritual más eficaz en España.

Orlega habla con gran simpatia de Buenos Aires: le preocupa cuanto allá se realiza. aunque estima que es aquella una cultura aún incipiente. Admira en la Argentina tres cosas formales: el sentido del mando; la vida rural, las estancias, el campo; y sus mujeres, que forman en el seno de su sociedad una especie de élite delicada.

- ¿Le gustan a usted las americanas, las argentinas?

Tanto. que por lo que toca a la Argentina, me parece que una de las cosas más admirables que tiene, según ya se lo decía, son sus mujeres. Yo estuve alli hace diez años. Los argentinos. a pesar de su orgullo no siempre bien fundado. me dejaron buena impresión: pero ellas, y no hablo de su belleza, me parecieron magnificas.

- Se dice... icuántas cosas se dicen de usledl... que estuvo enamorado de $\mathrm{V}$. O.

-Qué mucho que se diga, si aunque no fué asi bien pudo serlo. Si usted leyó el epilogo que escribí para .De Francesca a Beatriz., se habrá dado cuenta de cómo me interesa su taIento. Y Victoria Ocampo, siendo interesentisima, no es lo más interesante todavia. Pero eso es justamente lo extraordinario de la Argentina. No es una mujer, son muchas las que seducen con un espiritu fino y superior. Sin pretender ofender la buena amistad que mantengo con los argentinos, le aseguro que deseo volver allá más por ellas que por ellos.

- ¿La interesan las otras mujeres de América?

-No conozco muchas. Fuera de Gabriela Mistral es María la única chilena que he visto. Me gustan el tipo y el espiritu criollos. La criolla tiene valores que no alcanzará jamás la europea: es valiente, juguetonamente audaz, apasionada, vibrante.

- ¿Y la española?

-Es otra cosa: me interesa muy poco. No le niego un sinnúmero de cualidades, de que en general la criollą carece: pero. como estamos refiriéndonos al espiritu, afirmo que la española no me gusta. 
- No ha faltado quien asegure que usted es todo un don Juan; vale decir un mujeriego.

- ¿Mujeriego yo? Tan poco lo soy que, cuando he leido las tentaciones de San Anlonio y de otros santos, he sentido el pasmo de lo que han tenido que hacer para dominar sus deseos. Por mi así me encerrasen con la Venus de Milo. no necesitaria flajelarme para mirarla tranquilamente. En ese terreno tengo cierta leminidad espiritual en cuanto participo de los sentimientos femeninos, que mueven a no amar a un hombre por hermoso si de uno u otro modo no ha logrado haccrse amar por su espiritu o por sus hechos. Yo soy susceptible de amar lo que ha comenzado por interesarme. La mujer posee esa condición: su cuerpo es, al mismo tiempo espíritu y por eso siente el pudor que no experimentan los hombres. Esconde su cuerpo como esconde sus pensamientos.

Calla un instante; enciende un pitillo y nos dice:

-El amor me parece maravilloso. una de las cosas más extraordinarias que se dan bajo el sol y en la cual la mujer es árbitro supremo. Sinceramenle enamorada, la mujer.posee el don genial del amor y llega a latifudes que nunca alcanzaremos los hombres.

Alguien habla del matrimonio y Ortega responde:

-El matrimonio es una institución social. No hace falta el amor en el matrimonio sino la cordialidad. la comprensión mutua, la amistad bondadosa. Puede darse el amor en el matrimonio, es claro, pero no se da sino rara vez y está bien así siempre.

- ¿No cree usted posible la amistad amorosa?

- La amistad amorosa. con su solo nombre me irrila. Es una cosa trunca, banal, literaria y absurda. Creo en la posible amislad de un hombre y una mujer como en un amor entre ambos. ipero no se hable de amistad amorosal

Tarde a la tarde $y$, antes de despedirnos, le decimos a Orlega:

- Pero hemos hablado de todo y de lodos, menos de usted: sus libros, sus arlículos, sus posibles próximos viajes... 
- Mis libros, mis articulos!. nos responde él mientras aspire el humo de su cigarrillo. ISi supiera cómo me cuesta escribir! Así como pensar no me demanda trabajo. pues lo hago hasta con cuarenta grados de fiebre, escribir me significa ponerme en un estado de agilidad, como quien se apronta para el salto: crearme un estado de simpatia especial. de verdadera disposición.

Recordamos lo que Araquistain nos decia cierta vez: A pesar de la inmensa cultura y de la extraordinaria inteligencia que tiene Ortega, es un improvisador: vive al dia, de lo que le sugiere el momento. Per eso no creo que emprenda alguna obra sistemática, de vasta arquitectura orgánica.

¿Entonces es inútil que pensemos en la futura sIntroducción a la Estimativa o ciencia de los valoress. en la cual hubiera reanudado la tradición que iniciaba èl propio Séneca o prometia una reconstrucción de la historia como un proceso de descubrimiento de los valores; ni en .La superación del subjetivismos. ya anunciadas: ni en las lecciones de su cáledra de metafisica en la Universidad Central?

$Y$. aunque no se lo preguntamos a Araquistain, desde el fondo de nuesira curiosidad interrogativa parece decirnos su afirmación: sí, tal vez sea inútil esperar de ese árbol otras flores que las fugitivas. frágiles y admirables de ese inconstante florecer.

\section{ALGO SOBRE LOS TOROS, LOS AMERICANOS Y OTRAS COSAS}

En el hotel Palace: huyendo del té de moda y del estrépito de su música, que no abandona del todo los timbales y los cobres del jazz-band. hemos ido a buscar quielo refugio en un rincón de la amplia rotonda del vestibulo, en este hotel magnifico que bien merece su nombre de palacio. De nuevo nos encontramos reunidos Rosa y José Oriega. Gustavo Pittaluga, Maria y el cronista que estas lineas hilvana.

Es la tercera vez que estamos con el doctor Pittaluga, este hombre amable y afable; pequeñito, como que todo en él es me- 
nudo y leve: los ojos, la voz, la cabeza, las manos. Rubio y algo miope, impone con su aire displicente, su voz mesurada. que pronuncia demasiado las palabras; con su no sé qué de estiramiento de primera reunión.

Rosa mantiene su serena inmutabilidad, que conslituye su mayor encanto. Ortega apura un pastelillo y gusta con fruición de la mermelada de fresas. Maria, muda, exhibe su aire ausente.

De pronto Pittaluga, por decir algo, comienza a hablar de los toros. Ortega bebe un sorbo de té sin poner reparos a esos ditirambos. Maria fija en él sus pupilas escrutadoras y Ortega no rehuye la interrogación. Se enjuga los labios y dice valientemente, aunque sabe que sụ respuesta le puede valer una encmiga apasionada:

-Si. Maria, me gustan los toros. ¡Oh, no me mire asi! Me gustan ¿qué quiere usted? $Y$ aún a riesgo de irrilar más ese semblante hasta hoy amigo. he de decirle que me parecen soberbios... ¿Qué? ¿Me va a argüir aquello de la sangre, deł público feroz, de los caballos destripados. de la crueldad del espectáculo? Pero, vea usted: vamos por partes. Las corridas de toros, desde luego, no se acabarán Ino. felizmentel ¿No advierte usted toda la locura que siguen despertando? Es que el espectáculo que le parece bárbaro a usted, no lo es porque es la encarnación de la belleza misma; sí. es la belleza misma... ¿Lo niega? No se puede negar eso, María, aunque quiera. Si la belleza no está en los banderilleros, ni en las capas rojas, ni en el traje de luces. ISi la belleza está en el desdén al peligro. en el riesgo del torero. en la absoluta falta de amor a la vida: ese villano amor a la vida que no siente el espada! Porque, mire usted, eso eleva al torero, un ser casi siempre vulgar, a desmesurada altura. Deja de ser un ser primitivo para convertirse en un ser superior. ¿En qué se distinguen las razas inferiores de las más elevadas? En que son infinitamente más susceptibles al terror que estas últimas... ¿Que el torero no se juega la vida? Pues ¿y qué es lo que hace en todo momento. sino jugársela segundo a segundo? $Y$ en cuanto al caballo lvaya un honor que se le hace! El caballo es un animal a quien el hombre honra 
haciéndole participe de una fiesta heroica. El caballo en el ruedo se dignifica como en el campo de batalla.

El último sorbo de té y. luegoo, un cigarrillo.

- ¿Que son útiles las batallas y las corridas no? ¿Y la utilidad de la belleza o su inutilidad, como usted quiera? ¿De cuándo acá la belleza necesitó de utilidad alguna?

María, irritada, nerviosa, le replica:

- Sofismas. Ortega; usted es un sofista terrible. Bien me decia. hace pocas horas, una amiga suya: Ortega tiene razón siempre, ya lo creo, como que dirá cualquier día, mostrándole esa planta: ¿¿ve usted? Es una planta. ¿Creía usted que era una planta? Pues está en un error.... ly te probará que es una piedra! Y tú no le darás crédito a tus ojos porque le creerás a él... Ya ve usted. Oriega, no quiero convencerme de que una corrida no es un espectáculo salvaje. No siģa hablando. Y, sépalo usted: desde estc momento lo admiro menos.

Orlega se rie. Con presleza recobra sus fueros de galantuomo. para replicar de muy buen humor.

- Maria, renuncio a las corridas de toros: si usled quiere renuncio.

Maria simula una sonrisa de paz y habla de ofra cosa. mientras Ortega se incorpora de su asiento. Su gran cabeza se recorla con claro relieve en el londo de bruma artificial de ese jardin de invierno. Viste un traje impecable que, en su corte modernísimo, parece hacer más delgado su cucrpo enjulo. que ciñe sin una arruga la perfecta americana. Se pasea un instante. alumbra una cerilla que acerca al pitillo y retorna a su asiento. - Ya no somos enemigos. le dice a María: renuncio a los toros, es un hecho.

- ¿Qué piensa usted de los americanos?. le interroga ella por toda respuesta. Sus opiniones deben ser bien desdeñosas ¿verdad?

-No, de ninguna manera: eso es falso. Los americanos. to sé por grata experiencia personal cuando estuve en Buenos Aires, tienen una extraordinaria intuición de las cosas y constituyen un público atento, enormemente seductor para todo aquel 
que desee dirigirse a ellos, hasta el punlo que han logrado que los tomen seriamente en cuenta. Y si no. lea usted o relea mi Carta a un joven argentino, en el volumen quinto de .El Espectador.. De lo que considero poco capaces a los americanos es de método. Además son soberbios. los argentinos al menos, y dudan en reconocer méritos fuera de su tierra. Estas dos condiciones perjudican cuanto podria dar su espiritu de pujante y de original. Yo no sé de ningún escritor americano realmente estudioso y bien disciplinado en lo que toca a observación y trabajo. Usted, por ejemplo: haga algo por corregirse organizándose y estudiando.

- ¿Cómo debo comenzar?

-Aprendiendo lenguas. Usted sabe el francés: siga con el alemán. No creo que se pueda ser un escritor completo si no se sabe el alemán. Es indispensable lecr una regular cantidad de libros en esa lengua, que no están traducidos y que tardarân en estarlo.

- Es usted un apasionado de las cosas alemanas.

Soy un apasionado de ellas porque son las mejores del mundo. La cultura de Alemania y por ende su ambiente son los más complelos c interesantes que hay. Podrian ser superiores lodavia pero, en fin, contentémonos con saber que son lo mejor que existe sobre la superficie del globo.

Calla un instante, porque el doctor Pittaluga le advierte que es tarde ya, bien entrada la noche, y agrega:

- No olvide este consejo desinteresado: usted, como cualquier escritor que anhele ser algo, debe venirse a vivir un tiempo largo a Madrid. No se imagine usted que esto, en cuanto a ambiente, me parezca el desideratum; al contrario. creo que es muy poca cosa. Pero es más que América. Además, aquí nos encontramos en Europa y a cualquiera le resulta fácil pasar largas temporadas en Berlín, indispensables desde el punto de vista cultural.

Por la noche, en breve, vigilia, hemos releido las magnificas páginas de aquella epístola a un joven argentino que estudia filosofia: cLa nueva generación, escribe en ella Ortega, goza de 
una espléndida dosis de fuerza vital. condición primera de toda empresa histórica: por eso espero en ella. Pero, a la vez, sospecho que carece por completo de disciplina interna, sin la cual la luerza se desagrega y volatiliza: por eso desconfio de ella. No basta curiosidad para ir hacia las cosas; hace falta rigor mental para hacerse dueño de ellas.s

Al dia siguiente, en la tertulia del Regina, le decimos a Araquistain, a! referirle la defensa acalorada de Ortega por los toros. que Eugenio Noel debería comenzar en su anti-flamenquismo derrolando a cuantos como Orlega y Pérez de Ayala son sus tenaces delensores. Pero Araquistain nos responde:

-No crea mucho en las lecciones de Orlega, que son las de un profesor un poco escéptico. hábil maestro en sofisterias. IDefender los toros! Yo también los defendería si se les constiluyera en un deporle en el cual participaran todos los hombres desde los quince hasla los treinta años. Porque avergüenza ver a las multitudes que, detrás de los tendidos, piden. rugen porque el torero se acerque al toro: que se juegue la vida para salisfacer su brutalidad. Si a csos cobardes se les obligara a bajar al ruedo y poner en juego su propio valor. España seria otra cosa y no este pueblo de cobardia colectiva, helado de marasmo. Que no se prohiban los toros sino que, se les transforme en deporte nacional y obligatorio, como el servicio militar y la doctrina cristiana en las escuelas. Que sean la escuela popular del peligro: es decir. lo contrario de lo que hoy son.

\section{EL NUEVO TEATRO, LA NOVELA Y LA SOCIEDAD}

En el recogido saloncito de nuestro hotel, en la Revista de Occidente, en casa de Gustavo Pittaluga o de Ricardo Baeza. encontramos con frecuencia a Orlega. Una noche nos dice a los devotos de su terfulia:

- Traigo una noticia interesante. Es preciso oirla... Extrae de su bolsillo una esquela y lee una breve carla de Azorin, en la 
cual le anuncia que ha terminado una .Judiths. que ha de poner en escena Margarila Xirgu.

Jacinto Grau se muestra sorprendido, asombrado. dudoso acaso de creer que el autor de .Doña Inés, pueda acercarse a la recia hembra biblica.

- ¿Qué le parece? ¿Qué le parece?. nos dice. mientras nosotros sólo alinamos a responderle:

- ¿Qué nos va a parecer, a pesar del claro talento de Azorin, después de la sudith, de Hebbel?

Sin embargo, imaginamos que, asi como el autor de ta ruta de don Quijote, se reveló excelente orador en un discurso memorable, puede resultar ahora un óptimo escritor dramático.

Entre tanto Ortega comienza a hablar brillantemente sobre el teatro nuevo:

- Es necesario, dice, comenzar por demoler cuanto existe. porque no vale nada, nada. En el ́eatro hay que crear algo novisimo. en que el espectáculo sea todo: los actores deben salir a primer plano y los autores desaparecer a recluirse en el segundo. Es preciso comenzar por los espectáculos de los bailes rusos, tan llenos de calor y de sugerencias artisticas. Nijinski. por ejemplo, no es algo absiracto: es preciso verle para lormarse idea sobre él. Un sallo de Nijinski es un salto que no puede ser descrito en un libro. Que venga el espectáculo y que desaparezca la literatura en el teatro. pues no hace falta.

Herminia Grau, esposa de Jacinto, actriz excelente, con su sentido modernísimo de la escena, bate palmas, mientras el autor de El hijo pródigo, apunta algunas reservas calurosas.

- Si, comprendo su indignación, Grau, le dice Orlega, pero es que yo estimo que están equivocados. siendo todo lo apreciable cuanto ustedes hacen. En la Revista de Occidente, una vez que se terminen sus nuevos salones, pienso iniciar la serie de espectáculos interesantes, que explicarán mejor lo que deseo. Por ejemplo. he encargado la música de un trozo para un Don Quijote antes que lo escribiera Cervantes, a manera 
de ensayo inicial a fin de intentar luego obras de mayor aliento. Será el Quijole mozo, enjulo, neurasténico. de veinticinco años. simple soñador. En la feria del Toboso ha visto a Aldonsa Lorenzo: le encontramos en el postrer acto lúcido de su vida, antes de volverse loco. Pero. como no es fácil descubrir un músico lo suficienlemente penelrado del espirilu moderno que yo quisiera imprimirle a esto. le he pedido que escriba la música para un solo fragmento. cuando Don Quijote vela las armas. Ya veremos si resulta.

El hijo mayor de Pillaluga asegura que el músico ha dado en el clavo: es hermoso aquello, muy hermoso y muy actuals. exclaina.

Araquistain. al recordar acaso licmpos de buena mocedad esludiantil convividos en Alemania, nos ha dicho que Ortega guarda una novela terminada. María, aprovechando un silencio. le dice:

- QQué deseos tengo de leer su novelal ¿Es cierlo que liene una novela terminada, desde hace algunos años?

- La novela es un género que une gusta. En hacer una buena novela estan cifrados todos mis esfuerzos. Veremos.

- ¿Tiene algo avanzado?

- Mucho. Desde luego está toda hecha in mente y tengo un sinnúmero de nolas. Abre una cartera y nos va alargando. una a una. cuartillas pequeñas. llenas de diálogos vivaces, de agudas reflexiones, de nombres, de referencias.

$-¿ \mathrm{Y}$ el asunto?

- iLas novelas de hoy tienen lan poco asunto! Pero he aqui algo del mio: un hombre de la clase media que se siente succionado de pronto hacia una esfera supcrior. hasta las altas clases de la sociedad.

- Claro está que ese hombre es usted.

- Tal vez sí y no. Todas las novelas tienen algo, mucho de autobiográficas.

-Es frecuente oir que a usled le preocupan y le interesan mucho las clases de la aristocracia.

- Eso es la verdad: yo fui un solitario durante mucho tiempo. 
Dentro de mi aislamiento, en mi sitial de espectador, me di cuenta entre otros problemas por resolver, que es preciso interesar a las clases altas por los artistas, por el arle, por las cosas de intelecto en general. Y quise, entonces, llegar hasta ellas, pero como se debe poner el pie en esos lugares, para dominarlos.

Cavila un instante, apura un sorbo de champagne y toma un confite que le ofrece la fina mano de una dama.

- Creo haber realizado una grata conquista, prosigue. Esas gentes tienen sus desventajas. como todas las gentes, pero tienen alğo de que no es fácil darse cuenta. En las aristocracias hispano americanas, que no cuentan más de un siglo, no puede darse nada semejante. No se inventan veinte abuelos y el que no los tiene tras de si no sabe lo que es sociabilidad. Yo voy a un salón y lengo alli todas las expectalivas: se puede conversar tan bien; cada frase es tan oportunamente acogida y tan bien devuelta. Es un juego apasionante ese juego de la palabra pensada y estudiada, que se lanza como una bala certera para producir un efecto preciso. A veces una réplica inesperada, a veces la sonrisa de una mujer que parecía imposible.

-Pero cacaso no puede darse lo propio en salones menos encumbrados pero acaso más seleclos?

-No, porque no hay mujeres: y nada puede ser menos en el mundo que una conversación sin ustedes. Sé que se me va a decir: ¿y las otras mujeres? No es lo mismo aunque sean hermosas, aunque sean letradas, aunque vibren fambién como las ofras. Les falta precisión, contorno: los veinte abuelos detrás, proyectando la sombra necesaria en el estrado de sus salones...

Goethe y Chateubriand anduvieron también perdidos en ese liviano juego del amor y de la frivolidad, que llega hasta nosotros como el perfume del siglo de Watleau... y de la Enciclopedia.

Pero des dable hablar de la frivolidad cuando se trata de todo un filósofo? Bien haya por el hombre mozo que, en el alborear de los veinte años, hace cada mañana el viaje de 
Simples conversaciones con Orfega y Gassef

Citeres: pero. no concebiriamos al Spinoza ni al Hegel de los cuarenta otoños perdido en el vano juego de la galantería. ILos cuarenta años que Taine deseaba para la primera obra de madurez!

Sin embargo, en Ortega y Gasset los rebrotes primaverales han venido a retoñar en hora tardia. ¿No desconocerian estas actuales Nofas del vago estio o aquella sobre una conversación en el golf las graves reflexiones que firmaba en Junio de 1908 el flamante universitario tudesco, en su ensayo alrededor de -El Santo, de Fogazzaro? De entonces, de aquel entonces. son las palabras siguientes: Todo hombre que piensa: la vida es una cosa seria. es un hombre intimamente religioso. La verdadera irreligiosidad es la falta de respeto hacia lo que hay encima de nosotros y a nuestro lado, y más abajo. La frivolidad es la impiedad, la asebeia maldita, asesina de razas, de ciudades, de individuos: ella debió ser la más grande lentación de San Antonio, y yo espero que vendrá un tiempo más sulil y profundo que el nuestro, en que, perdonándole al Diablo todas sus jugarretas en lo conscupiscible, se le excecre tan sólo porque es un ser frivolo.s

¡Un ser frivolo! ¿Qué mala venganza ha querido jugarle al aduslo pensador de treinta años el espiritu avieso de Mefistófeles tornándole ligero. elegante, gracioso. fino.... frivolo, digámoslo de una vez? ¿O será que se ha cumplido en él aquello que pedia Nietzsche: Vivid en peligro; el peligro de acercar un poco la filosofia al amor, porque ya pensaba él que sla meditación es ejercicio eróticos. y el éros platoniano no es más que la inducción que mueve a penetrar en el sentido de las cosas. No. no: estamos distantes ahora del amor puramente conceptual; es decir, del amor en su proyección casi metafisica.

Ahora Ortega, como Proust, no puede, no quiere, dejar de pensar también du coté de chez Swann. Al escribir su primera novela, acaso le encontremos como al admirable joven maestro francés, perdido en el mundo pueril de la distinción y de los salones, aguordando en el recodo de algún camino el paso de 
la noble señora o compartiendo la amistad de cualquiera de sus ayudas de cámara para lograr admirarla más de cerca.

iTiempos menguados estos que corren para los destinos de la distinción y la galanteria!

\section{SIMPLES PARALIPÓMENOS}

Nada más que fugaces pinceladas para un retrato algo intimo, pretenden ser estas páginas, sazonadas gracias a la sal de indiscreciones con que el cronista, tocado de boswelliana curiosidad. las ha ido condimenlando. ¿Acaso no está bien fresco el recuerdo de Anatole France, cuyo espírilu es dable conocer tan hondamente en la lectura de los libros de Gsell y de Brousson. para no citar los de tantos otros que. como abejas indiscretas. han venido a revolar sobre la cabeza del oclogenario yacente? Por lo demás, la lección es muy anfigua, tanto que no la desperdiciaron los discipulos de Sócrates y le dió carácter de maestria aquel caballero que siguió los pasos del escritor Johnson, como Aeckermann lué tras los de Goethe.

Extraordinario causeur Ortega y Gasset, animador de ideas. buen sofista y maestro de la paradoja, podría. según dijera de Rivarol alguno de sus contemporáneos, vivir para deleitar con el don de su plática sabrosa y fina, no menos grata que sụs libros. ¿Qué mucho entonces que la pícara indiscreción de tal - cual de sus oyentes haya querido perpeluar el aroma de esas charlas, ya que no le era dable aprisionar la forma primorosa de su expresión?

En el discurrir colidiano de esa vida icuántas cosas habrán de ser imaginadas en la conversación que. siri embargo. escaparán al libro, que siempre atemoriza con su carácler de eternidadl Porque todo lo que en la plática nos permite conocer al hombre intimo, al hombre intaclo en su sinceridad sin reservas, no siempre se nos da en la lefra impresa. molde demasiado temerario para encarar la estulticia del bildungphilister. que decia Nictzsche. 
Han sido hilvanados eslos simples recuerdos en la paz que brinda el tranquilo mar de los trópicos. lejos de la urbe distanle y de las tierras americanas. sin más contactos ni referencias que el puente ideal lendido hacia los recientes días vividos por la desprevenida memoria, más esquiva y menos fiel que una doncella en flor de primavera. 